\section{Rheumatic heart disease with a mitral blood cyst: three-dimensional echocardiographic imaging}

A 22-year-old woman presented with a 4-month history of dyspnoea on exertion and palpitations. She was in New York Heart Association class II at presentation. She had no history of fever, joint pains or rash. On examination, she had a grade II pansystolic murmur at the apex and an early diastolic murmur at the aortic area. Laboratory investigations revealed anti-streptolysin $\mathrm{O}$ titre of $<200$ units with normal erythrocyte sedimentation rate and $\mathrm{C}$ reactive protein levels. On two-dimensional echocardiographic examination, the mitral valve showed mild leaflet thickening with a mobile globular cystic structure with no internal echoes (figure 1), attached to the posterior mitral leaflet, producing moderate mitral regurgitation (figure 1). The aortic valve showed leaflet thickening and retraction leading to severe aortic regurgitation. Three-dimensional echocardiographic en-face views of the mitral valve from left atrial (figure 2A, online Supplementary video 1 ) and left ventricular aspects (figure 2B, online Supplementary video 2) clearly defined the globular structure attached to the P-2 and P-3 scallops of the mitral valve with a broad base near the posteromedial

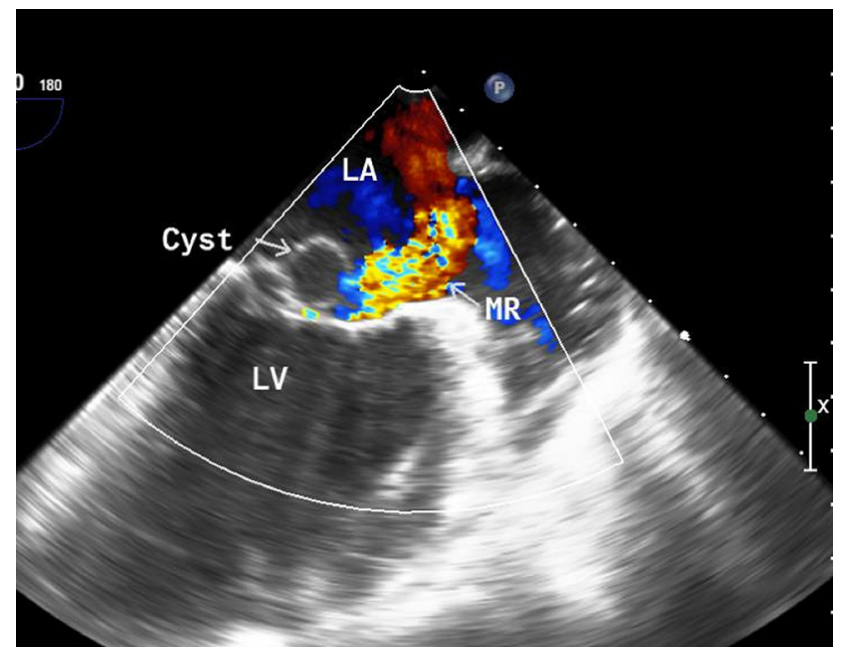

Figure 1 Two-dimensional transoesophageal echocardiographic images showing a globular cystic structure attached to the mitral valve with moderate MR. LA, left atrium; LV, left ventricle; MR, mitral regurgitation.
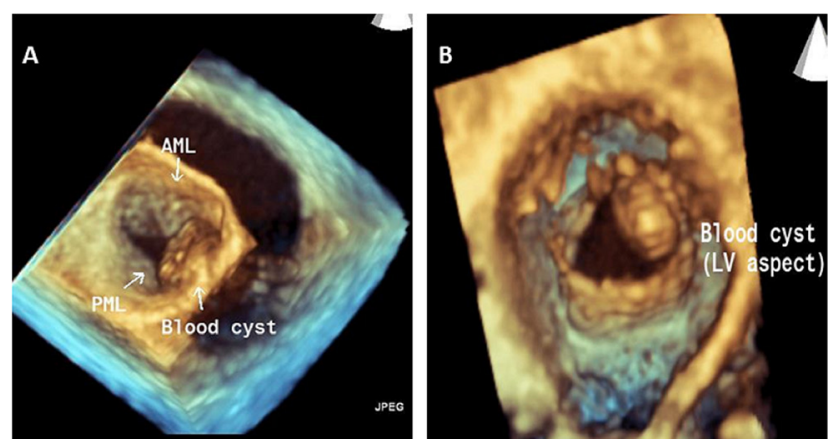

Figure 2 Three-dimensional transoesophageal echocardiographic images showing an en-face view of the mitral valve from a left atrial aspect with a globular cystic structure attached near the base of the P-2 and $P$-3 scallops (A); an en-face view from a left ventricular aspect with the cyst bulging into the mitral orifice (B). LV, left ventricle. AML: Anterior mitral leaflet, PML: Posterior mitral leaflet

commissure. Based on the above findings, a diagnosis of rheumatic heart disease (RHD) with severe aortic regurgitation and moderate mitral regurgitation with a blood cyst of the mitral valve was made. Blood cysts are congenital benign lesions that generally regress with age ${ }^{1}$ and hence are rarely seen in adults. ${ }^{2}$ Their coexistence with RHD has seldom been reported. The patient successfully underwent a double valve replacement.

Gajendra Dubey, Anand Shukla, Tarun Madan

Department of Cardiology, UN Mehta Institute of Cardiology and Research Center, Civil Hospital, Ahmedabad, Gujarat 380016, India

Correspondence to Dr Gajendra Dubey, UN Mehta Institute of Cardiology and Research Center, Civil Hospital, Asarwa, Ahmedabad, Gujarat 380016, India; gajendra.dubey119@gmail.com

Contributors All the authors have contributed significantly towards generation of this report and meet the criteria for authorship.

Competing interests None declared.

Provenance and peer review Not commissioned; internally peer reviewed.

(c) Article author(s) (or their employer(s) unless otherwise stated in the text of the article) 2017. All rights reserved. No commercial use is permitted unless otherwise expressly granted.

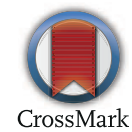

To cite Dubey G, Shukla A, Madan T. Heart Asia 2017;9:1

Heart Asia 2017;9:1. doi:10.1136/heartasia-2017-010897

\section{REFERENCES}

Dencker M, Jexmark T, Hansen $F$, et al. Bileaflet blood cysts on the mitral valve in an adult. J Am Soc Echocardiogr 2009;22:1085.e5-8.

2 Park MH, Jung SY, Youn HJ, et al. Blood cyst of subvalvular apparatus of the mitral valve in an adult. J Cardiovasc Ultrasound 2012;20:146-9. 